\title{
Two-Dimensional Flow Through the Uniformly Porous Horizontal Pipe with Thermal Radiation and Cross-Diffusion Effects
}

\author{
Nagaraju Gajjela $^{1 *}$, Mahesh Garvandha², Anjanna Matta ${ }^{1}$ \\ ${ }^{1}$ Department of Mathematics, Faculty of Science and Technology, ICFAI Foundation for Higher Education, Hyderabad \\ 501203, Telangana, India \\ ${ }^{2}$ Department of Mathematics, GITAM (Deemed to be University), Hyderabad Campus, Rudraram(V), Sangareddy District, \\ Telangana 502329, India
}

Corresponding Author Email: nagaraju.gajjela@ifheindia.org

https://doi.org/10.18280/mmc_b.891-404

Received: 14 November 2019

Accepted: 9 October 2020

\section{Keywords:}

Newtonian fluid, suction, pipe, thermal radiation, cross-diffusions, stream function, homotopy parameter

\begin{abstract}
This paper is dedicated to the mathematical analysis of an axisymmetric, steady Newtonian fluid flow through a horizontal pipe within the occurrence of radiation, Dufour, and Soret effects. The flow is exposed to associate outwardly functional constant suction above the pipe along Z-direction. The homotopy analysis methodology (HAM) is utilized to get semi-analytical solutions for the coupled differential equations. The results of diverse rising constraints on velocities, thermal and solutal are discussed and pictured. The flow is studied through streamlines, isotherms and pressure contours area unit likewise shown as pictured. It is identified that the temperature can increase with an increase in Dufour parameter but decelerates with an improvement in the radiation parameter. For the given increase within the Soret number, the concentration decelerates.
\end{abstract}

\section{INTRODUCTION}

The study of flow through permeable boundaries has several important industrial applications such as biophysics, lubrication technology, spatial dynamics, blood flow through arteries and veins, and control of boundary layers. From this viewpoint, the porous channel/pipe problems of similar model type have been studied by many researchers (Berman [1], Terril and Shrestha [2], Zaturska and Banks [3]. Bujurke et al. [4], Erdogan and Imrak [5], Devakar and Iyengar [6]). The other interesting problems for porous boundaries with different geometrics can be seen in Ramana Murthy et al. [7], Nagaraju and Ramana Murthy [8], Srinivas et al. [9], and Aparna et al. [10]. It is documented that heat and mass transport are mixed as a result of the fluid density depends on thermal and solutal. In the power and chemical industries, coupling laminar heat and mass transfer can be found. In many engineering applications such as heat exchangers, solar thermal collectors, and boilers, double-diffusive convection in circular tubes in laminar flow occurs. Of explicit interest is the problem of derivation within the thermal entrance incompressible flow along a pipe with a fully improved velocity distribution; this problem is resulted to as the Graetz problem. It has drawn interest not only from engineers but also from mathematicians due to the difficulties in deriving its solution. Ganesan and Loganathan [11] have studied the double-diffusive viscous flow through a semi-infinite vertical cylinder. The Double-diffusive natural convection was examined by Mani Sankar [12] through a vertical open-ended cylindrical annulus. He found that the number of Sherwood is decreasing as the radii ratio increases. Brahim and Jemni [13] investigated a two-dimensional Darcy-BrinkmanForchheimer heat tube's thermal analysis. Okafor et al. [14] studied the distribution of non-symmetric heat flux through a mixed horizontal convective tube.

The Dufour effect is the heat flux caused by a gradient of concentration that was resulted in 1873 by Dufour as a coupled effect of irreversible systems; it is referenced to as the thermodiffusion effect. The effect of Dufour is of such magnitude that it cannot be disregarded. On the other hand, the Soret effect (thermo-diffusion) is a phenomenon experimental in mobile particle mixtures where different particle types react differently to the temperature gradient force. The effects of Soret and Dufour are important because the effect of Soret is used for the separation of isotopes, electrostatic precipitators, drug discovery, etc. Several researchers studied and reported results for such fluid flows, due to importance of the importance of the cross-diffusion effects for very light and medium molecular weights fluids (Nabil et al. [15], Rani and Reddy [16], Srinivas et al. [17], Odelu and Naresh kumar [18], Nagaraju et al. [19, 20].)

Yang and Ebadian [21] examined in a circular tube the mixture of axial conductivity and axial radiation. Yih [22] used a convective isothermal vertical cylinder to investigate radiation and porous medium effects. Ganesan and Loganathan [23] examined the effect of radiation on flow past a semi-infinite vertical cylinder that was impulsively started. They identified the radiation parameter increases, the fluid's speed and the temperature rise sharply near the cylinder. The other interesting studies on radiative heat and mass transfer flow by diverse geometries can be found in Govardhan et al. [24], Nagaraju et al. [25], and Abdullah Al-Mamun et al. [26].

The survey exhibits that two-dimensional viscous flow with cross-diffusion and radiation has not been studied elsewhere. Therefore, the objectives of this study are to mathematically solve the steady viscous flow problem through a horizontal 
pipe subjected to cross-diffusion and radiation for the fully developed region, and derive completely analytical solutions for the fluid thermal profile and concentration using HAM (Liao [27]). With the help of planned graphs, the consequence of connected parameters on the distribution of thermal and concentration was discussed thoroughly.

\section{MATHEMATICAL MODELING}

Fluid thought of during this study is Newtonian with fully developed flow through a horizontal pipe of radius ' $a$ ' in occurrence of cross-diffusion and thermal radiation. By constant wall temperature and concentration on the pipe surface, the heat and mass transfer method are studied. The fluid flow is subjected to constant external suction inside the conventional path through the wall. Backed by these assumptions, the dimensional equations of the fields of viscous liquid, thermal and solute are expressed as follows.

$$
\begin{gathered}
\frac{\partial W}{\partial Z}+\frac{1}{R} \frac{\partial}{\partial R}(R U)=0 \\
\rho\left(U \frac{\partial}{\partial R}+W \frac{\partial}{\partial Z}\right) U=-\frac{\partial P}{\partial R}+\mu\left(\frac{\partial}{\partial R}\left(\frac{\partial U}{\partial R}+\frac{U}{R}\right)+\frac{\partial^{2} W}{\partial Z^{2}}\right) \\
\rho\left(U \frac{\partial}{\partial R}+W \frac{\partial}{\partial Z}\right) W=-\frac{\partial P}{\partial Z}+\mu\left(\frac{\partial^{2} W}{\partial Z^{2}}+\frac{1}{R} \frac{\partial W}{\partial R}+\frac{\partial^{2} W}{\partial R^{2}}\right) \\
U \frac{\partial T}{\partial R}+W \frac{\partial T}{\partial Z}=\frac{k}{\rho C_{p}}\left(\frac{\partial^{2} T}{\partial R^{2}}+\frac{1}{R} \frac{\partial T}{\partial R}+\frac{\partial^{2} T}{\partial Z^{2}}\right) \\
+\frac{D K_{T}}{C_{s} C_{p}}\left(\frac{\partial^{2} C}{\partial R^{2}}+\frac{1}{R} \frac{\partial C}{\partial R}+\frac{\partial^{2} C}{\partial Z^{2}}\right) \\
-\frac{1}{\rho C_{p}} \frac{1}{R} \frac{\partial}{\partial R}\left(R q_{R}\right) \\
\left(U \frac{\partial}{\partial R}+W \frac{\partial}{\partial Z}\right) C \\
=\quad D\left(\frac{\partial^{2} C}{\partial Z^{2}}+\frac{1}{R} \frac{\partial C}{\partial R}+\frac{\partial^{2} C}{\partial R^{2}}\right) \\
+\frac{D K_{T}}{T_{m}}\left(\frac{\partial^{2} T}{\partial Z^{2}}+\frac{1}{R} \frac{\partial T}{\partial R}+\frac{\partial^{2} T}{\partial R^{2}}\right)
\end{gathered}
$$

with

$$
\begin{gathered}
U=\frac{\partial W}{\partial R}=\frac{\partial T}{\partial R}=\frac{\partial C}{\partial R}=0 \text { at } \mathrm{R}=0 \\
U=v_{0}, W=0, T=T_{w} \text { and } C=C_{w} \text { at } \mathrm{R}=a
\end{gathered}
$$

Introducing the dimensionless variables

$$
\begin{gathered}
U=u v_{0}, W=w v_{0} R=r a, P=p \rho v_{0}^{2}, Z=a z, \boldsymbol{T}= \\
\theta\left(T_{w}-T_{\infty}\right)+T_{\infty}, C=\phi\left(C_{w}-C_{\infty}\right)+C_{\infty}
\end{gathered}
$$

We consider that $\mathrm{q}_{\mathrm{R}}$ under the Rossel and approximation has the following form:

$$
q_{R}=-\frac{4 \sigma^{*}}{3 k^{*}} \frac{\partial T^{4}}{\partial R}
$$

Substitute in Eqns. (1)-(7), we get the governing dimensionless equations as:

$$
\begin{gathered}
\frac{\partial w}{\partial z}+\frac{1}{r} \frac{\partial}{\partial r}(r u)=0 \\
\operatorname{Re}\left(u \frac{\partial}{\partial r}+w \frac{\partial}{\partial z}\right) u=-\operatorname{Re} \frac{\partial p}{\partial r}+\left(\frac{\partial}{\partial r}\left(\frac{\partial u}{\partial r}+\frac{u}{r}\right)+\frac{\partial^{2} w}{\partial z^{2}}\right) \\
\operatorname{Re}\left(u \frac{\partial}{\partial r}+w \frac{\partial}{\partial z}\right) w=-\operatorname{Re} \frac{\partial p}{\partial z}+\left(\frac{\partial^{2} w}{\partial z^{2}}+\frac{1}{r} \frac{\partial w}{\partial r}+\frac{\partial^{2} w}{\partial r^{2}}\right) \\
\operatorname{RePr}\left(u \frac{\partial \theta}{\partial r}+w \frac{\partial \theta}{\partial z}\right) \\
=\nabla^{2} \theta+\operatorname{Pr}_{f} \nabla^{2} \phi \\
\operatorname{ReSc}\left(u \frac{\partial^{2} \theta}{\partial r^{2}}+\frac{1}{r} \frac{\partial \theta}{\partial r}\right) \\
f=D^{2} f=\frac{\partial \theta}{\partial r}=\frac{\partial \phi}{\partial r}=0 \text { at } \mathrm{r}=0 \\
f^{\prime}=0, f=\theta=\phi=1 \quad \text { at } \mathrm{r}=1
\end{gathered}
$$

The Laplacian operator defined as $\nabla^{2}=\frac{\partial^{2} \theta}{\partial r^{2}}+\frac{1}{r} \frac{\partial \theta}{\partial r}+\frac{\partial^{2} \theta}{\partial z^{2}}$, $\operatorname{Re}=\frac{\rho v_{0} a}{\mu}, \operatorname{Pr}=\frac{\mu c_{p}}{k}, D_{f}=\frac{D K_{T}\left(C_{w}-C_{\infty}\right)}{v c_{S} C_{p}\left(T_{w}-T_{\infty}\right)}, S c=\frac{v}{D}, R_{d}=$ $\frac{16 T_{\infty}^{3} \sigma^{*}}{3 k k^{*}}$ and $S r=\frac{D K_{T}\left(T_{w}-T_{\infty}\right)}{v T_{m}\left(C_{w}-C_{\infty}\right)}$.

The stream function $\psi$ is defined to be:

$$
u=-\frac{\psi_{z}}{r} \text { and } w=\frac{\psi_{r}}{r}
$$

From (11) and (12), the pressure (p) is removed, produces:

$$
\operatorname{Re}\left(-\frac{2}{r^{3}} \psi_{z} E^{2} \psi+\frac{1}{r^{2}}\left(\psi_{z} \frac{\partial E^{2} \psi}{\partial r}-\psi_{r} \frac{\partial E^{2} \psi}{\partial z}\right)\right)=\frac{-E^{2}\left(E^{2} \psi\right)}{r}
$$

where, $E^{2}=\frac{\partial^{2}}{\partial r^{2}}-\frac{1}{r} \frac{\partial}{\partial r}+\frac{\partial^{2}}{\partial z^{2}}$.

The following form is supposed for $\psi[2]$.

$$
\psi=(N-z) f(r)
$$

Substituting Eq. (19) in (18), results in,

$$
\operatorname{Re}\left(\frac{3 f f^{\prime \prime}}{r^{2}}-\frac{3 f f^{\prime}}{r^{3}}-\frac{f f^{\prime \prime \prime}}{r}+\frac{f f^{\prime \prime}}{r}-\frac{f^{\prime 2}}{r^{2}}\right)=-D^{4} f
$$

where, $D^{2}=\frac{d^{2}}{d r^{2}}-\frac{1}{r} \frac{d}{d r}$ is a differential operator.

At the surface of the pipe the shear stress, thermal, and solutal fluxes and can be derived from:

$$
C_{f}=\frac{2 \bar{\tau}_{r z}}{\rho v_{0}^{2}}, N u=\frac{a q_{h}}{k\left(T_{w}-T_{\infty}\right)} \text { and } S h=\frac{a q_{m}}{D\left(C_{w}-c_{\infty}\right)} \text { at } R=
$$


where,

$$
\left\{\begin{array}{c}
\bar{\tau}_{r Z}=\frac{\mu v_{0}}{a} \frac{(N-z)}{r} D^{2} f \\
q_{h}=-k \frac{\partial T}{\partial R}=\frac{-k\left(T_{w}-T_{\infty}\right)}{a} \frac{\partial \theta}{\partial r} \text { at } r=1 \\
q_{m}=-D \frac{\partial C}{\partial R}=\frac{-D\left(C_{w}-C_{\infty}\right)}{a} \frac{\partial \phi}{\partial r}
\end{array}\right.
$$

The dimensionless form of (21) is given by:

$$
\left\{\begin{array}{c}
C_{f}=\frac{2(N-z)}{R e} D^{2} f \\
N u=-\frac{\partial \theta}{\partial r} \quad \text { at } r=1 \\
S h=-\frac{\partial \phi}{\partial r}
\end{array}\right.
$$

\section{THE HOMOTOPY SOLUTION}

The given initial approximations of $\mathrm{f}_{0}(\mathrm{r}), \theta_{0}(r)$ and $\phi_{0}$ are derived for HAM solutions as:

$$
f_{0}(r)=2 r^{2}-r^{4}, \theta_{0}(r)=1 \text { and } \phi_{0}(r)=1
$$

with the auxiliary operators are:

$$
L_{2}=L_{3}=\nabla^{2} \text { and } L_{1}=D^{4}
$$

with

$$
\begin{gathered}
L_{1}\left[c_{1} r^{4}+c_{2}\left(2 r^{2} \log r-r^{2}\right)+c_{3} r^{2}+c_{4}\right]=0 \\
L_{2}\left[(N-z)^{2}\left(c_{5}+c_{6} \log r\right)+c_{7} r^{2}\right. \\
\left.+c_{8} r^{2}(\log r-1)\right]=0 \\
L_{3}\left[(N-z)^{2}\left(c_{9}+c_{10} \log r\right)+c_{11} r^{2}\right. \\
\left.+c_{12} r^{2}(\log r-1)\right]=0
\end{gathered}
$$

where, $C_{i}(\mathrm{i}=1$ to 12$)$ are constants. $\mathrm{h}_{\mathrm{i}}(\mathrm{i}=1,2,3)$ (regulator parameters) are used in zeroth-order deformation equations.

The zeroth-order deformations; non-linear operators $\mathrm{N}_{\mathrm{i}}(\mathrm{i}=1$ to 3 ) are considered as described in the effort of Nagaraju et al. $[28,29]$.

\section{DISCUSSION OF RESULTS}

The flow Eqns. (11)-(14) subject to the border line conditions (15) to (16) are coupled, hence the system of equations is solved semi-analytically using the Homotopy method. For the convergent series solutions, we have picked the values of $\mathrm{h}_{1}=0.4, \mathrm{~h}_{2}=-0.5$ and $\mathrm{h}_{3}=-0.8$ through the permissible range of $h$ values based on $h$ curves as shown in Figures 1(a)-1(c).

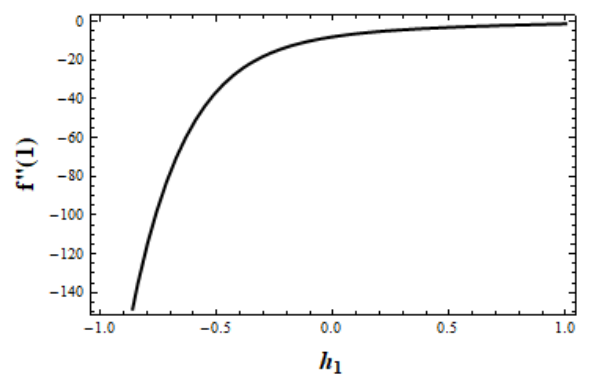

(a)

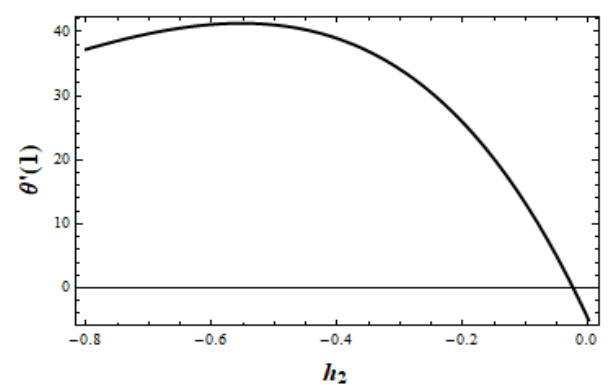

(b)

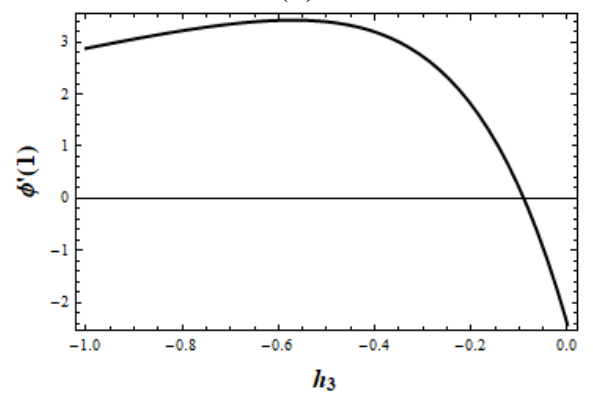

(c)

Figure 1. h-curves for (a) velocity, (b) thermal and (c) concentration

Figures 2(a)-2(f) present the nature of $f, f^{\prime}, \theta$ and $\phi$ under the influence of Re. Out of Figure 2(a) as Re enhances, the $f$ increases. It is observed that $f^{\prime}$ enhances up to the point $r=0.6$ then there is a decrement in the axial velocity as $R e$ increases from Figure 2(b). Figures 2(c)-2(f) shows that an increase in $R e$ results in a rise in radial $\theta$ levels, $\phi$, and decreases in axial $\theta$.

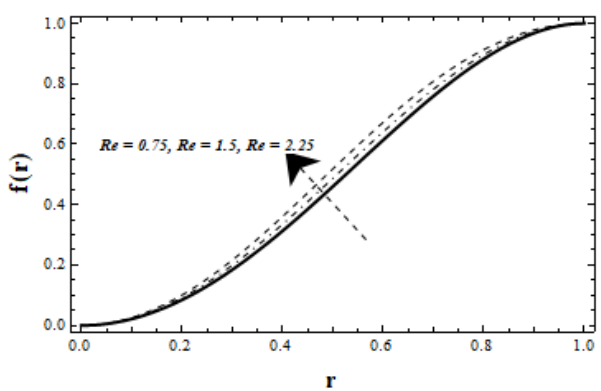

(a)

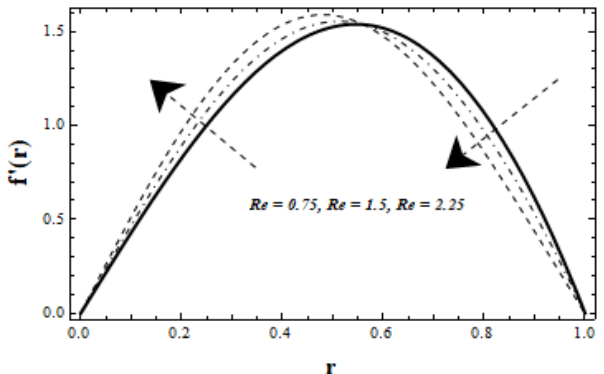

(b)

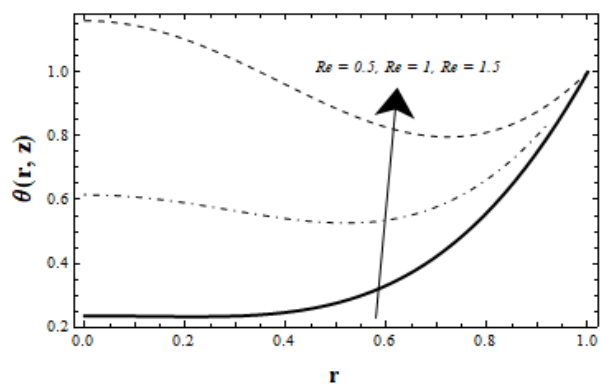

(c) 


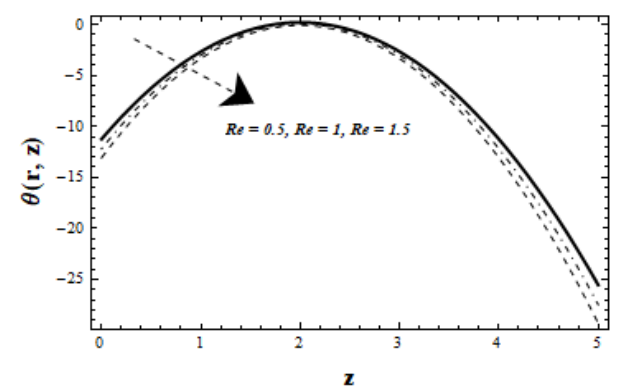

(d)

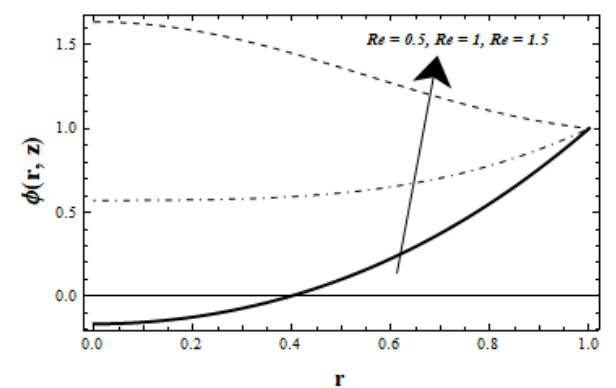

(e)

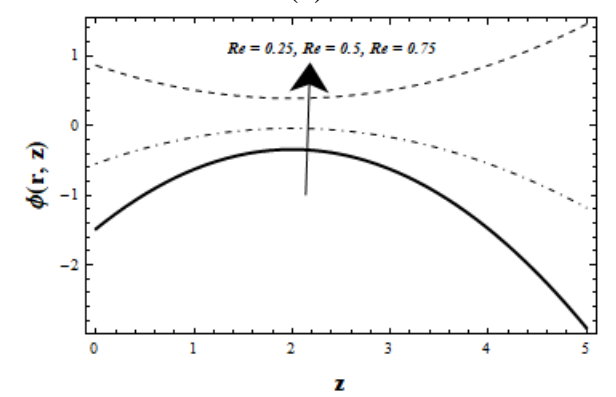

(f)

Figure 2. Variation of Reynold number on (a) $f$, (b) polar velocity, (c) radial $\theta$, (d) axial $\theta$, (e) radial $\phi$, and (f) axial $\phi$

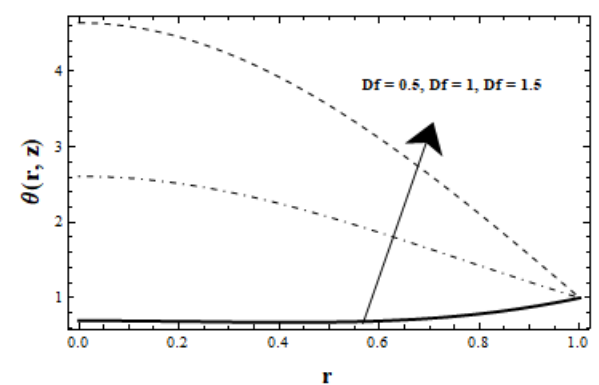

(a)

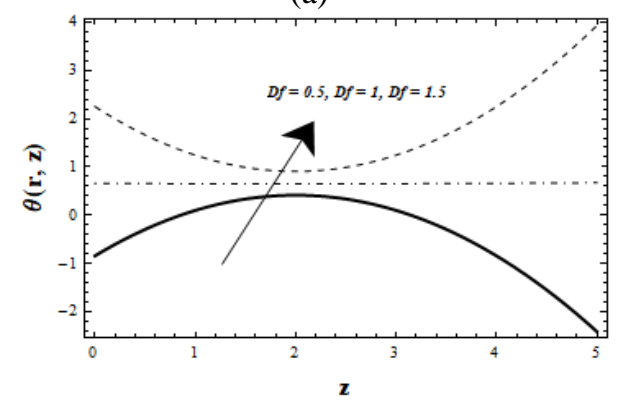

(b)

Figure 3. Variation of Dufour number on (a) radial $\theta$, (b) axial $\theta$

From Figures 3(a)-3(b) we can see that radial and axial temperature increases as the Dufour number increases. From
Figures 4(a)-4(b), we can observe that radial and axial temperature decreases as the radiation parameter rises. These results show that the radiation has significant dominance in the flow field. It can be shown in Figures 5(a)-5(b) that radial and axial $\theta$ enhances as the Prandtl number increases.

It is clear from Figures 6 and 7, it can be resulted that radial and axial concentration decreases as $S c$ and $S r$ increases. It is identified that Nusselt and Sherwood number raises with Prandtl and Schmidt number raises in Figures 8 and 9 respectively. It is noticed from Figure 10, that velocity streamlines are non-negative at $z \leq N$ and negative at $z>N$. For $z=N$, the Streamlines are numerically symmetric. It can be shown from Figure 11 that $\theta$ is symmetrical about the line $z=N$. From Figure 12, it is observed that concentration is symmetric about $z=N$ and increments as $r<0.8$.

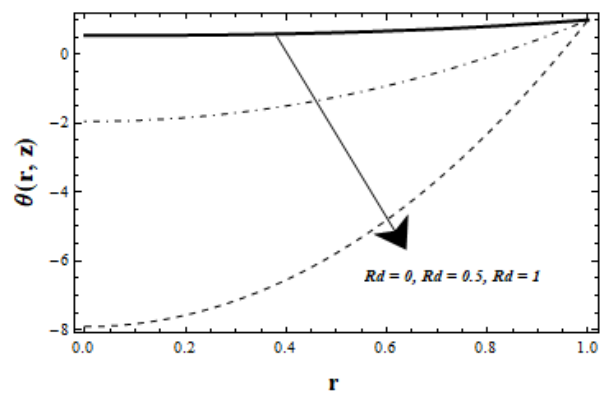

(a)

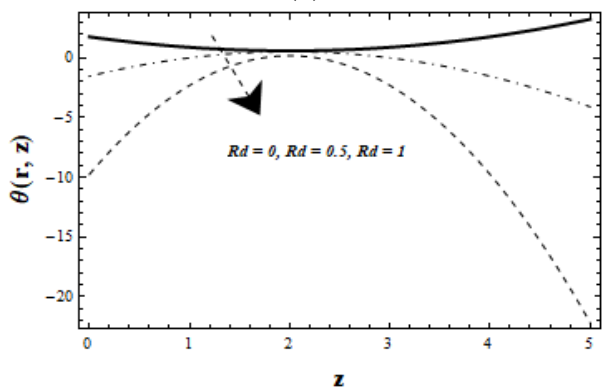

(b)

Figure 4. Variation of Radiation on (a) radial $\theta$, (b) axial $\theta$

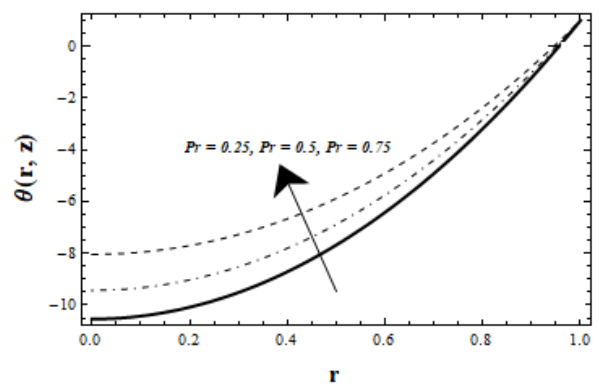

(a)

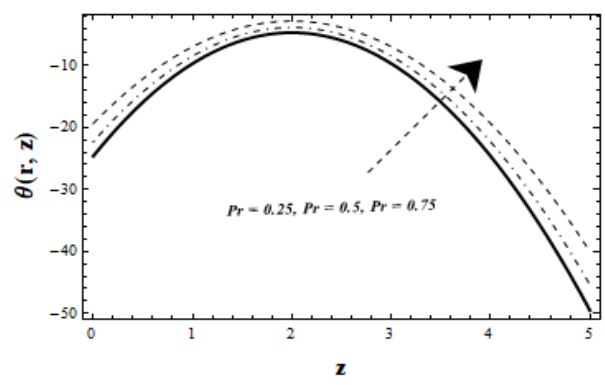

(b)

Figure 5. Variation of Prandtl number on (a) radial $\theta$, (b) axial $\theta$ 


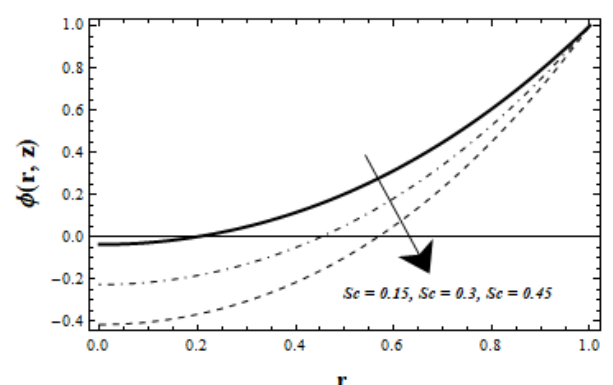

(a)

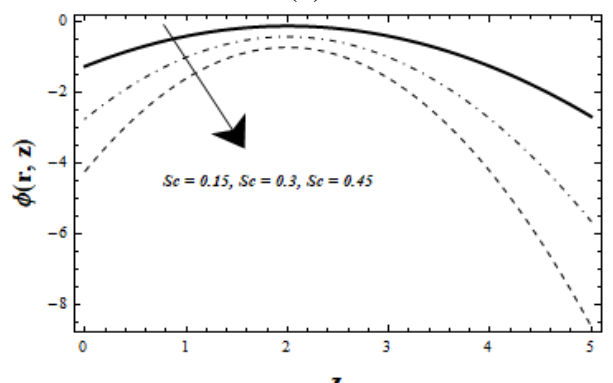

(b)

Figure 6. Impact of $S c$ on (a) radial $\phi$, (b) axial $\phi$

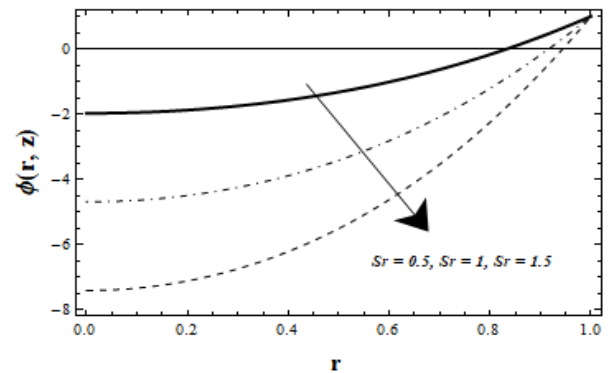

(a)

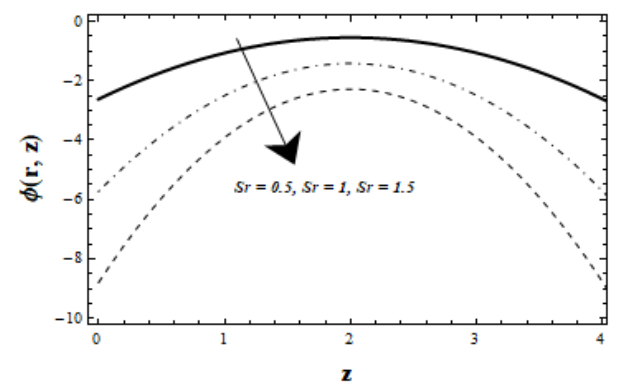

(b)

Figure 7. Impact of $S r$ on (a) radial $\phi$, (b) axial $\phi$

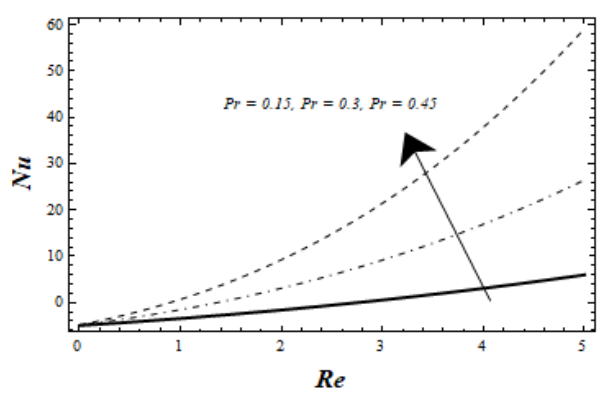

Figure 8. Changes of $\mathrm{Pr}$ on $\mathrm{Nu}$

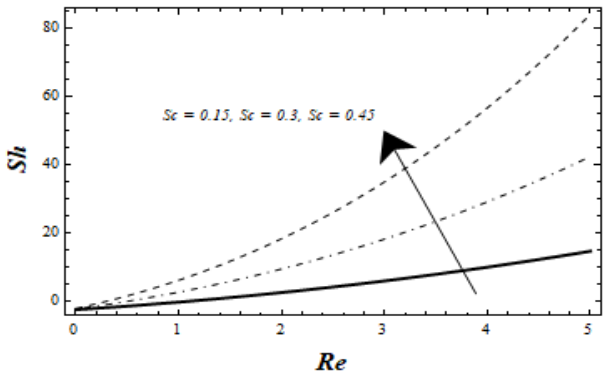

Figure 9. Changes of $\mathrm{Sc}$ on $\mathrm{Sh}$

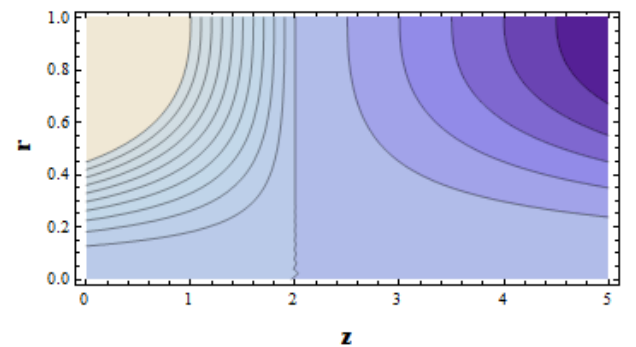

Figure 10. Velocity streamlines

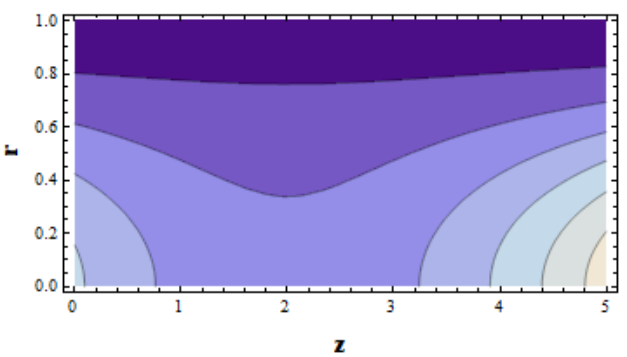

Figure 11. Contour graph for Temperature isotherms

Table 1. Nature of skin friction coefficient, heat and mass transfer rates for various values of $R e, S r$, and $D f$

\begin{tabular}{|c|c|c|c|c|c|c|c|c|c|}
\hline$R e$ & $z$ & $P r$ & $S c$ & $S r$ & $D f$ & $R d$ & $\mathbf{C}_{\mathrm{f}}$ & $\mathrm{Nu}$ & Sh \\
\hline 0.75 & & & & & & & -17.2233 & 3.85944 & 4.52758 \\
\hline 1.5 & 1 & 071 & 05 & 1 & 006 & 15 & -5.98985 & 24.722 & 14.2953 \\
\hline 2.25 & 1 & 0.11 & 0.5 & 1 & 0.00 & $1 . J$ & -1.81603 & 53.0241 & 27.0234 \\
\hline & & & & & 0.5 & & & 27.0956 & 48.0487 \\
\hline 1.5 & 1 & 0.71 & 0.5 & 1 & $\begin{array}{c}1 \\
1.5\end{array}$ & 1.5 & -- & $\begin{array}{l}29.7929 \\
32.4902\end{array}$ & $\begin{array}{l}61.5916 \\
75.2606\end{array}$ \\
\hline & & & & 0.5 & & & & 37.607 & 38.5889 \\
\hline 1.5 & 1 & 0.71 & 0.5 & $\begin{array}{c}1 \\
1.5\end{array}$ & 0.5 & 1.5 & -- & $\begin{array}{l}37.9793 \\
38.3515\end{array}$ & $\begin{array}{c}50.872 \\
63.1551\end{array}$ \\
\hline
\end{tabular}




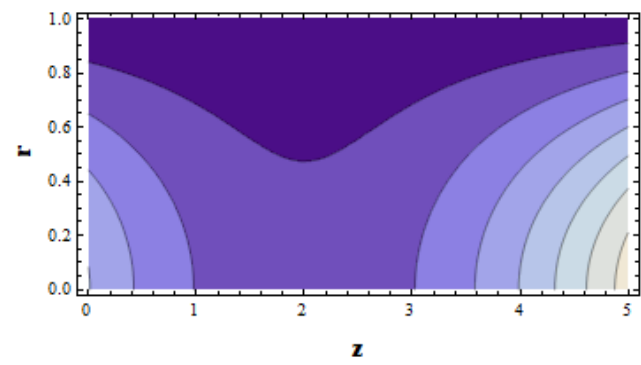

Figure 12. Contour graph for concentration

The nature of the $C_{f}, N u$, and $S h$ with the flow parameters can be seen in Table 1. The results from Table 1 that the $N u$ and $S h$ increase as $R e, S r$ and $D f$ increase.

\section{CONCLUSION}

This paper addresses the mathematical analysis of an axisymmetric, steady Newtonian fluid flow through a horizontal pipe in the occurrence of radiation and Crossdiffusion effects. Based on results through the HAM, summarily the findings as follows:

i. The Reynolds number breaks the axial flow and increases the radial flow.

ii. An increment in $\operatorname{Pr}$ and $D f$ causes an increase in the temperature profiles whereas $\theta$ decreases as $R d$ increases.

iii. The concentration profile rises upon increasing the $R e$, and decreases as $S r$, and $S c$ increases.

iv. The Skin-friction $\left(C_{f}\right)$, Nusselt number $(N u)$, and Sherwood number $(S h)$ increase as $R e$ raise.

v. The Nusselt number $(\mathrm{Nu})$, and Sherwood number (Sh) increases when $\mathrm{Pr}$ and $\mathrm{Sc}$ number raises.

\section{ACKNOWLEDGMENT}

The authors are grateful to the anonymous referees for remarks which improved the work considerably.

\section{REFERENCES}

[1] Berman, A.S. (1953). Laminar flow in channels with porous walls. J. Appl. Phys., 24(9): 1232-1235. http://dx.doi.org/10.1063/1.1721476

[2] Terril, R.M., Shrestha, G.M. (1965). Laminar flow through parallel and uniformly porous walls of different permeability. ZAMP, 16: 470-482. https://doi.org/10.1007/BF01593923

[3] Zaturska, M.B., Banks, W.H.H. (1995). Flow in a pipe driven by suction at an accelerating wall. Acta Mechanica, 110 :

111-121. https://doi.org/10.1007/BF01215419

[4] Bugurke, N.M., Madalli, V.S., Mulimani, B.G. (2000). Laminar flow in a uniformly porous pipe. Indian $\mathrm{J}$. of Pure appl. Math., 31(3): 341-352.

[5] Erdog, M.E., Imrak, C.E. (2005). On the axial flow of an incompressible viscous fluid in a pipe with a porous boundary. Acta Mechanica, 178: 187-197. https://doi.org/10.1007/s00707-005-0247-x

[6] Devakar, M., Iyengar, T.K.V. (2008). Stoke's problems for an incompressible couple stress fluid. Nonlinear Analysis Modelling and Control, 1(2): 181-190. https://doi.org/10.15388/NA.2008.13.2.14578

[7] Ramana Murthy, J.V., Nagaraju, G., Muthu, P. (2012). Micropolar fluid flow generated by a circular cylinder subject to longitudinal and torsional oscillations with suction/injection. Tamkang Journal of Mathematics, 43(3): $339-356$. https://doi.org/10.5556/j.tkjm.43.2012.329-356

[8] Nagaraju, G., Ramana Murthy, J.V. (2013). MHD flow of longitudinal and torsional oscillations of a circular cylinder with suction in a couple of stress fluid. Int. J. of Applied Mechanics and Engineering, 18(4): 1099-1114. https://doi.org/10.2478/ijame-2013-0069

[9] Srinivas, J., Adesanya, S.O., Falade, J.A., Nagaraju, G. (2017). Entropy generation analysis for a radiative micropolar fluid flow through a vertical channel saturated with non-darcian porous medium. Int. J. Appl. Comput. $\quad$ Math., 3: 3759-3782. http://dx.doi.org/10.1007/s40819-017-0322-8

[10] Aparna, P., Ramana Murthy, J.V., Nagaraju, G. (2018). Couple on a rotating permeable sphere in a couple stress fluid. Ain Shams Engineering Journal, 9(4): 665-673. https://doi.org/10.1016/j.asej.2016.03.012

[11] Ganesan, P., Loganathan, P. (2001). Unsteady natural convective flow past a moving vertical cylinder with heat and mass transfer. Heat and Mass Transfer, 37: 59-65. https://doi.org/10.1007/s002310000128

[12] Mani, S. (2010). Numerical study of double diffusive convection in partially heated vertical open ended cylindrical annulus. Adv. Appl. Math. Mech., 2(6): 763783. https://doi.org/10.4208/aamm.09-m0997

[13] Brahim, T., Jemni, A. (2014). Effect of the heat pipe diabatic region. Journal of Heat Transfer, 136(4): 042901 https://doi.org/10.1115/1.4025132

[14] Okafor, I.F., Dirker, J., Meyer, J.P. (2017). Asymmetrical non-uniform heat flux distributions for laminar flow heat transfer with mixed convection in a horizontal circular tube. Heat Transfer Engineering, 40(1-2):

$1-78$. https://doi.org/10.1080/01457632.2017.1421055

[15] El Dabe, N.T., Moatimid, G.M., Ali, H.S.M. (2002). Rivlin-ercksen fluid in tube of varying cross-section with mass and heat transfer. Zeitschrift für Naturforschung A, 57(11): 863-873. https://doi.org/10.1515/zna-2002-1105

[16] Rani1, H.P., Reddy, G.J. (2013). Soret and dufour effects on transient double diffusive free convection of couplestress fluid past a vertical cylinder. Journal of Applied Fluid Mechanics, 6(4): 545-554.

[17] Srinivas, S., Shukla., A.K., Ramamohan; T.R., Reddy, S.A. (2014). Influence of thermal radiation on unsteady flow over an expanding or contracting cylinder with thermal-diffusion and diffusion-thermo effects. Journal of Aerospace Engineering (ASCE), 28(5): 04014134. https://doi.org/10.1061/(ASCE)AS.1943-5525.0000470

[18] Ojjela, O., Kumar, N.N. (2016). Chemically reacting micropolar fluid flow and heat transfer between expanding or contracting walls with ion slip, Soret and Dufour effects. Alexandria Engineering Journal, 55(2): 1683-1694. https://doi.org/10.1016/j.aej.2016.02.026

[19] Gajjela, N., Matta., A., Kaladhar, K. (2017). The effects of Soret and Dufour, chemical reaction, Hall and ion currents on magnetized micropolar flow through corotating cylinders. AIP Advances, 7(11): 1-16. 
https://doi.org/10.1063/1.4991442

[20] Nagaraju, G., Shilpa, S., Matta, A. (2018). MHD flow of micropolar fluid in the annular region of rotating horizontal cylinders with cross diffusion, thermophoresis, and chemical reaction effects. Numerical Heat Transfer and Fluid Flow, Lecture Notes in Mechanical Engineering, 399-407. https://doi.org/10.1007/978-98113-1903-7_46

[21] Yang, G., Ebadian, M.A. (1991). Thermal radiation and laminar forced convection in the entrance region of a pipe with axial conduction and radiation. Int. J. Heat and Fluid Flow, 12(3): 202-209. https://doi.org/10.1016/0142727X(91)90053-X

[22] Yih, K.A. (1999). Radiation effect on natural convection over a vertical cylinder embedded in porous media. Int. Comm. Heat Mass Transfer, 26(2): 259-267. https://doi.org/10.1016/S0735-1933(99)00012-3

[23] Ganesan, P., Loganathan, P. (2002). Radiation and mass transfer effects on the flow of an incompressible viscous fluid past a moving vertical cylinder. International Journal of Heat and Mass Transfer, 45(21): 4281-4288. https://doi.org/10.1016/S0017-9310(02)00140-0

[24] Govardhan, K., Nagaraju, G., Kaladhar, K., Balasiddulu, M. (2015). MHD and radiation effects on mixed convection unsteady flow of micropolar fluid over a stretching sheet. Procedia Computer Science, 57: 65-76. https://doi.org/10.1016/j.procs.2015.07.366

[25] Nagaraju, G., Matta, A., Kaladhar, K. (2016). Effects of chemical reaction and thermal radiation on heat generated stretching sheet in a couple stress fluid flow. Frontiers in Heat and Mass Transfer, 7(11): 1-5. http://dx.doi.org/10.5098/hmt.7.11

[26] Al-Mamun, A., Arifuzzaman, S.M., Reza-E-Rabbi, S.M., Biswas, P., Khan, S. (2019). Computational modelling on MHD radiative Sisko nanofluids flow through a nonlinearly stretching sheet. Int. J of Heat Tech., 37(1): 285-295. https://doi.org/10.18280/ijht.370134

[27] Liao, S.J. (2012). Homotopy Analysis Method in Nonlinear Differential Equations. Springer Heidelberg, Germany.

[28] Nagaraju, G., Srinivas, J., Ramana Murthy, J.V., Beg, O.A., Kadir, A. (2019). Second law analysis of flow in a circular pipe with uniform suction and magnetic field effects. ASME Journal of Heat Transfer, 141(1): 012004. https://doi.org/10.1115/1.4041796

[29] Nagaraju, G., Garvandha, M. (2019). Magnetohydrodynamic viscous fluid flow and heat transfer in a circular pipe under an externally applied constant suction. Heliyon, 5(2): e01281. https://doi.org/10.1016/j.heliyon.2019.e01281

\section{NOMENCLATURE}

\begin{tabular}{|c|c|}
\hline $\mathrm{w}, \mathrm{W}$ & $\begin{array}{l}\text { Non-dimensional and dimensional axial } \\
\text { velocity, } \mathrm{m} / \mathrm{s}\end{array}$ \\
\hline $\mathrm{u}, \mathrm{U}$ & $\begin{array}{l}\text { non-dimensional and dimensional radial } \\
\text { velocity, } \mathrm{m} / \mathrm{s}\end{array}$ \\
\hline $\mathrm{Cp}$ & specific heat, $\mathrm{J}_{\mathrm{kg}} \mathrm{kg}^{-1} \mathrm{~K}^{-1}$ \\
\hline $\mathrm{k}$ & thermal conductivity, W. $\mathrm{m}^{-1} \cdot \mathrm{K}^{-1}$ \\
\hline Tw & surface/wall temperature \\
\hline $\mathrm{Nu}$ & local Nusselt number along the heat source \\
\hline $\mathrm{D}$ & Diffusion coefficient \\
\hline $\mathrm{Tm}$ & mean temperature \\
\hline $\mathrm{CS}$ & Concentration susceptibility \\
\hline $\mathrm{v0}$ & suction/injection velocity \\
\hline $\mathrm{Re}$ & Reynolds number \\
\hline $\operatorname{Pr}$ & Prandtl number \\
\hline$E^{2}$ & Stoke's operator \\
\hline $\mathrm{T}, \mathrm{C}$ & The fluid temperature and concentration \\
\hline $\mathrm{N}=\mathrm{U}_{0} / \mathrm{v}_{0}$ & Constant velocity \\
\hline U0 & inlet velocity \\
\hline Df & Dufour parameter \\
\hline $\mathrm{Sc}$ & Schmidt number \\
\hline $\mathrm{Rd}$ & radiation parameter \\
\hline $\mathrm{Sr}$ & soret number \\
\hline $\mathrm{T}_{\infty}$ & temperature far away from the center \\
\hline $\mathrm{C}_{\mathrm{w}}$ & concentration at the wall \\
\hline $\mathrm{C}_{\infty}$ & concentration far away from the center. \\
\hline $\mathrm{k}^{*}$ & mean absorptioncoefficient. \\
\hline $\mathrm{K}_{\mathrm{T}}$ & Thermal-diffusion ratio \\
\hline
\end{tabular}

\section{Greek symbols}

$\begin{array}{ll}\rho & \text { fluid density, } \mathrm{kgm}^{-3} \\ \mu & \text { viscosity } \\ \sigma^{*} & \text { Stefan-Boltzmann constant }\end{array}$

